NOTICE: this is the author's version of a work that was accepted for publication in Journal of Banking and Finance. Changes resulting from the publishing process, such as peer review, editing, corrections, structural formatting, and other quality control mechanisms may not be reflected in this document. Changes may have been made to this work since it was submitted for publication. A definitive version was subsequently published in Journal of Banking and Finance, Volume 37, Issue 7, July 2013, Pages 2501-2509. http://dx.doi.org/10.1016/j.jbankfin.2013.02.006 


\title{
Rewards for downside risk in Asian markets
}

This Version: February 12, 2013

\begin{abstract}
Distributional properties of emerging market returns may impact on investor ability and willingness to diversify. Investors may also place greater weighting on downside losses, compared to upside gains. Using individual equities in a range of emerging Asian markets, we investigate the potential contribution of downside risk measures to explain asset pricing in these markets. As realized returns are used as a proxy for expected returns, we separately examine conditional returns in upturn and downturn periods, in order to successfully identify risk and return relationships. Results indicate that co-skewness and downside beta are priced by investors. Further testing confirms a separate premium for each measure, confirming that they capture different aspects of downside risk. Robustness tests indicate that, when combined with other risk measures, both retain their explanatory power. Tests also indicate that co-skewness may be the more robust measure.
\end{abstract}

JEL Classification: G12; G15; O16

Keywords: Downside risk; Emerging markets; Risk exposure and returns 


\section{Introduction}

The purpose of this paper is to explore whether measures of downside risk contribute towards an explanation of the risk/reward relationship for individual shares in emerging Asian markets. The notion that measures such as co-skewness and downside beta should matter to investors is well established in the literature. Kraus and Litzenberger (1976) show that utility functions with non-increasing absolute risk aversion imply a preference for positive skewness. Huang and Litzenberger (1988) demonstrate that the risk premium on assets will depend on their co-skewness, with investors preferring assets with positive co-skewness. The rational Disappointment Aversion (DA) utility function attributed to Gul (1991) implies that investors display a larger aversion to losses relative to the attraction for gains. Ang, Chen, and Xing (2006) demonstrate how, in a DA utility framework, cross sectional asset pricing will incorporate a premium for downside risk measures such as downside beta. Emerging markets merit separate examination, as there is evidence that asset returns exhibit very high volatility and are not normally distributed (Bekaert and Harvey, 1997). Bekaert, Erb, Harvey, and Viskanta (1998) identify significant skewness and kurtosis in emerging market returns, and they observe the persistence of skewness over time.

Co-skewness of returns is our primary measure of downside risk. Using individual share data, Harvey and Siddique (2000) find that co-skewness has explanatory power for share returns, after allowing for other established explanatory factors. Downside beta is a further indicator of downside risk. Ang, Chen, and Xing (2006) provide a detailed empirical examination of the explanatory power of downside beta for individual shares in the U.S. market. They show that the shares which co-vary 
strongly with the market during market downturns do have higher average returns. Pedersen and Hwang (2007) also demonstrate that downside beta will explain a higher proportion of individual U.K. share returns than will beta alone.

The issue of downside risk in emerging markets has already been addressed in the literature. Studies so far have examined this issue at aggregate market level, but not at the individual firm level. Estrada (2002) uses market indices to provide evidence on the explanatory power of downside beta. Using a measure developed from the comparison of investment returns with market portfolio returns, when each is below their respective means, he reports stronger results than for beta. When compared with downside beta, Galagedera and Brooks (2007) find that co-skewness is the better explanatory variable of emerging market monthly returns. Galagedera (2009) also reports that, when compared with beta and downside beta, co-skewness is a better measure of risk. However, when assessing developed market indices, he finds that both downside risk measures perform poorly when compared to beta.

Using daily data from emerging Asian markets, we present a series of empirical examinations of whether downside risk is independently priced in cross-section. We exclude Singapore and Hong Kong, as they would not normally be categorized as emerging markets. We also limit our investigation to eight markets, as remaining markets in this region are so small that they have relatively few actively traded shares. For our investigation, we compare realized returns of individual companies with individual risk measures computed in each market. As realized returns are a proxy for expected returns, we analyze returns during market downturns separately from market upturns. Our results offer a significant contribution to the unraveling and 
understanding of risk measures in emerging markets and the manner in which investors are rewarded for assuming those risks. In outline, we find that investors in emerging markets are clearly rewarded for exposure to both co-skewness and downside beta. Control tests confirm a separate premium for each, indicating they capture different aspects of downside risk. When combined with other risk measures, both co-skewness and downside beta retain explanatory power. There is however some evidence that co-skewness may be a more robust measure, as it tends to retain greater significance.

Our paper proceeds as follows. In Section 2 we outline details of the markets included in the study, we also address the issue of thin trading and share selection. Section 3 describes the research methodology. A separate sub-section models expected relationships between exposure to risk measures and investor returns. Section 4.1 presents an assessment of relationships between individual downside risk measures and returns, Section 4.2 offers the results of control tests on the potential impact of interrelationships between risk measures, and Section 4.3 contains results of regression tests on the explanatory power of risk measures, when in combination. Section 5 concludes.

\section{Data and markets}

Data from eight emerging national equity markets in the Asia Pacific region are included. These are China ${ }^{1}$, India, Indonesia, Malaysia, Pakistan, Taiwan, Thailand, and South Korea. All data comes from Thomson Data-stream. Daily prices for firms on each market are gathered over the ten year period from June $1^{\text {st }} 1999$ to May $31^{\text {st }}$

\footnotetext{
${ }^{1}$ We only consider 'A' list shares, quoted in China. We also do not distinguish between the Shanghai and Shenzhen markets.
} 
2009. Market capitalization is taken as the measure of company value, and annual values are also gathered for all firms. The measure of short-term interest rates for each market is as follows: the interbank overnight repo rate (China); the overnight call rate (India); the interbank call rate (Indonesia); the daily interbank rate (Malaysia); the KIBOR overnight rate (Pakistan); the daily overnight rate (South Korea); the overnight interbank rate (Taiwan); and the interbank overnight rate (Thailand). All national market indices are DS indices, they offer an estimate of dividend adjusted returns $^{2}$. They are value weighted, and they cover a minimum of seventy-five percent of total market value. Company value and data availability determines inclusion in the index, and the largest value companies in each market are selected.

Table 1 presents outline summary information on these markets. Values are from June $1^{\text {st }} 2008$, the beginning of the final year of data in our study. Total number of companies listed in each market is indicated, and market capitalization of all listed companies is the measure of total market value. Total market values, average values, and median values are detailed in both local currency and in US \$s, using currency exchange rates on this date.

-Table 1 approximately here-

\footnotetext{
${ }^{2}$ Details on the construction of DS (Data-stream) Indices are available in 'The Data-stream Global Equity Indices User Guide, Thomson Financial Limited 2003. The return index represents the theoretical growth in value of a notional stock holding, the price of which is that of the selected price index. This holding is deemed to return a daily dividend, which is used to purchase new units of the stock at the current price. The gross dividend is used. Full details on the construction of DS return indices are available in the user guide (page 20).
} 
Using either total value or average value as a measure, we note differences in scale between markets. After a period of sustained growth, the Chinese ' $A$ ' list market is largest, however the Indian market is of similar scale. Korea and Taiwan form a second group, as all remaining markets are considerably smaller. A comparison between mean and median values indicates the extent of domination by the biggest companies in each market. The Chinese market has the least skewed distribution of sizes, and most closely resembles the patterns observed in developed markets. To a lesser extent, India and Taiwan also exhibit a pattern of sizes that is close to that in the developed markets. All remaining markets are dominated by small numbers of large companies. We indicate the proportion of total value represented by the largest twenty percent of all companies in each market.

An obvious concern is that, since there are large numbers of small thinly traded shares in emerging markets, an accurate estimation of their risk attributes will not be possible. We therefore limit our investigation to the largest twenty percent of firms listed in each market, as this should reduce the influence of very small companies and curtail the impact of non-synchronous trading on estimated risk measures ${ }^{3}$. This sample selection should also ensure that similar proportions of each market are included. As indicated in Table 1, the firms in our sample represent in excess of eighty percent of total market value, in all eight markets. They will also be the firms of most interest to investors. Using market capitalization on June $1^{\text {st }}$, all firms are ranked every year, and the largest twenty percent in each market are selected. A further selection criterion is employed, as even relatively large companies may suffer a lack of liquidity (Feldman and Kumar, 1995). For all shares, in every year, we

\footnotetext{
${ }^{3}$ We believe that this screen filters out the potential data problems associated with small firms, identified in Ince and Porter (2006).
} 
estimate the proportion of days with zero returns. Lesmond, Ogden, and Trczinka (1999) propose this is a useful measure of transaction costs, it also provides a good approximation of the extent of thin trading. We specify fifty percent of zero returns as the maximum cut-off. Only those shares recording a proportion of zero daily returns below fifty percent are included when selecting the largest firms from each market. This second criterion results in the exclusion of a small number of larger companies ${ }^{4}$.

The study period covers ten years, from June $1^{\text {st }} 1999$ to May $31^{\text {st }} 2009$. Because of the desirability of a long study period, the possibility of extending back before 1999 was considered. During the 1990s, there has been rapid growth in overall size, and in the number of shares quoted in these markets. Levels of trading of individual shares have also increased. Had an earlier start date been selected, the number of companies meeting the minimum criterion percentage of zero daily returns is considerably lower, requiring a reduction in the proportion of each market included in our study sample, or a reduction in the number of national markets in our study. Our choice of start date therefore represents a compromise.

\section{Methodology}

\subsection{Risk measures}

Because all risk measures vary depending on the time horizon over which they are estimated, and also because actual risk exposures alter over time, we adapt the approach of Kothari, Shanken and Sloan (1995). All are estimated over a twelve

\footnotetext{
${ }^{4}$ Levels of thin trading in the smaller markets and also in the Thailand market are such that it would not have been possible to include more than twenty percent of shares in these markets, without including companies that do not meet the criteria of less than fifty percent zero returns.
} 
month horizon, from June $1^{\text {st }}$ to May $31^{\text {st }}$, using daily observations. They are tested in cross-section for their ability to explain annual company returns over the same period. Unlike those studies which form portfolios based on pre-formation measures, shares are sorted on realized factors in the same period as returns. We focus on contemporaneous relationships between factor loadings and returns, as in Lewellen and Nagel (2006), Ang, Chen and Xing (2006), and others.

We adapt the approach of Pettengill, Sundaram, and Mathur (1995). They recommend an explicit recognition of the impact of using realized returns as a proxy for expected returns, as it may be difficult to empirically establish relationships between returns and some risk measures. We form two sub-samples, one containing company returns during one year periods of downturn, and one for returns during periods of upturn. A downturn period is defined as a year in which overall market returns are below the market risk-free rate. A year in which market returns exceed their risk-free rates is designated as an upturn period. An examination of our data indicates that approximately half of all periods are designated as downturns, and half as upturns. All markets experience upturns and downturns, however Korea has experienced more downturn years than any other market. India and Pakistan have experienced the greatest number of upturn years. Most markets experienced a downturn in 2008, whereas the best performance was in 2006, when most recorded an upturn. We cannot forecast whether individual markets will in future deliver upturns or downturns, so our split-sample tests can offer no indication of the future long-run pricing of each risk measure, these only indicate if a relationship with realized returns can be identified. 
We combine data from all eight markets when evaluating of our risk estimates. As all are considered to be emerging markets, we assume that they share similar attributes, and that relationships between risk measures and company returns will be similar. In effect, we view these markets as being representative of a particular category of market. We also recognize that individual companies are traded on a particular market. When estimating many risk measures, company returns are compared with returns on a market index representing the market in which that company is listed. These measures therefore represent the exposure of locally based investors, rather than the international investor. In markets where restrictions on foreign equity investment exist, such as in India and Malaysia, the dominant investor group is likely to be local investors. In markets where foreign investment restrictions have been relaxed, a majority ownership of equity probably is still held by local investors, as opposed to global investors. For example Wang (2007) reports that in Indonesia and Thailand, two countries that could be considered to be representative of the more open emerging Asian markets, the equity holdings of foreign investors is between $25-30 \%$ in each market ${ }^{5}$.

Co-skewness $(C s k w)$ is our first measure of downside risk. Our empirical estimator is as follows:

$$
C s k w=\frac{\frac{1}{N-1} \sum_{t=1}^{N}\left(r_{i t}-\bar{r}\right)\left(r_{m t}-\bar{r}_{m}\right)^{2}}{\sqrt{\frac{\sum_{t=1}^{N}\left(r_{i t}-\bar{r}\right)^{2}}{N-1}} \frac{\sum_{t=1}^{N}\left(r_{m t}-\overline{r_{m}}\right)^{2}}{N-1}}
$$

\footnotetext{
${ }^{5}$ We recognize that, in the case of smaller national markets, the underlying CAPM may be misspecified. However risk measures constructed in this way are more representative of the exposures experienced by a majority of investors in these markets.
} 
In all cases, $r_{i}$ is daily return on share $i$, and $\bar{r}$ is average return. Index returns are indicated by $m$, so that $r_{m}$ is daily return on a national market index, and $\overline{r_{m}}$ is average market return.

We also consider two related idiosyncratic measures of risk, the skewness (Skew) of returns, and the variance of returns (Var). Our empirical estimator for skewness of returns is:

$$
\text { Skew }=\frac{N^{2}}{(N-1)(N-2) \frac{\frac{1}{N} \sum_{t=1}^{N}\left(r_{i t}-\bar{r}\right)^{3}}{\sqrt[3]{\frac{1}{N-1} \sum_{t=1}^{N}\left(r_{i t}-\bar{r}\right)^{2}}}}
$$

The estimator for volatility or variance of returns is:

$$
\operatorname{Var}=\frac{\sum_{t=1}^{N}\left(r_{i t}-\bar{r}\right)^{2}}{N-1}
$$

Downside betas $\left(\beta^{-}\right)$are computed when market return is below its mean ${ }^{6}$. For reasons of completeness, upside betas $\left(\beta^{+}\right)$are included. They are computed when market return is above its mean. We also compute relative downside and relative upside beta. They are included, as by construction, beta, downside beta, and upside beta are not independent of each other. They focus on the incremental effect of downside beta over beta, and of upside beta over beta. Using the concept of downside risk introduced by Bawa and Lindenberg (1977), each is estimated as follows:

\footnotetext{
${ }^{6}$ This differs from the split used when adapting Pettengill et al., where the terms 'upturn' and 'downturn' refer to a split dependent of whether market return is above or below the risk-free rate. In order to differentiate, we apply the terms 'upside' and 'downside' when referring to risk measures constructed using company returns conditioned on market returns either above or below their yearly averages.
} 
Downside beta is a measure of the covariance of a stock's returns with the market when the market is below average. The estimator is:

$$
\beta^{-}=\frac{\operatorname{Cov}\left(r_{i}, r_{m} \mid r_{m}<\overline{r_{m}}\right)}{\operatorname{Var}\left(r_{m} \mid r_{m}<\overline{r_{m}}\right)}
$$

Relative downside beta is:

$$
\operatorname{Rel}\left(\beta^{-}\right)=\beta^{-}-\beta
$$

Upside beta is a measure of the covariance of a stock's returns with the market when the market is above average. It is:

$$
\beta^{+}=\frac{\operatorname{Cov}\left(r_{i}, r_{m} \mid r_{m}>\overline{r_{m}}\right)}{\operatorname{Var}\left(r_{m} \mid r_{m}>\overline{r_{m}}\right)}
$$

Relative upside Beta is:

$$
\operatorname{Rel}\left(\beta^{+}\right)=\beta^{+}-\beta
$$

Beta $(\beta)$ is computed in the conventional way, by comparing each individual share return with its national market index return.

\subsection{Risk-return relationships in upturns and downturns}

In Table 2 we specify expected relationships between exposure to individual risk measures and investor returns. As well as an overall relationship, we also consider likely relationships during market upturns and downturns. Exposure to volatility is unattractive to investors, so we expect higher rewards will be required to attract investors to shares exhibiting high levels of variance. Variance is likely to be 
associated with both upturns and downturns, so we cannot specify a separate relationship in either period. We also have no expectation that skewness of returns will have a particular linkage to market upturns or downturns. This also implies no separate relationships between skewness and returns. Over all periods, we expect that a preference for positive skewness will cause investors to accept lower returns, so we expect a negative relationship between skewness and returns.

- Table 2 approximately here-

Beta should have a positive relationship with investor returns. Pettengill et al (1995) however show that a positive relationship may only exist during market upturns. A negative relationship is likely during downturns, as shares with greater exposure will offer poorer returns. When upturn and downturn periods are combined, the overall relationship should depend on whether there are greater numbers of upturn periods or downturn periods in a study period. In a growing economy, upturn periods are more likely, so a positive relationship is expected. Downside beta is of similar construction to beta, except that it is solely conditioned on observations when market performance is below average. As this risk exposure also is unattractive to investors, excess returns are required, so a positive relationship is expected. During downturns, investors accepting high downside beta should suffer relatively greater losses, we therefore expect a negative relationship. Investors should be compensated by greater rewards during upturn periods, which when combined with their downturn experiences, should provide superior overall returns. In contrast, upside beta is conditioned on observations when market returns are greater than their mean. Exposure to upside beta should be associated with higher returns when markets perform well, so a positive 
relationship with realized returns is expected. Shares exhibiting strong levels of upside beta will be attractive to investors, so they should accept relatively lower overall returns. They will expect relatively poor returns during downturns, when a negative relationship is likely.

Although an indicator of downside risk, co-skewness is constructed differently to downside beta, so it may capture separate aspects of an investor's risk exposure. It represents the contribution of an individual share to the skewness of a broader portfolio. We expect a negative overall relationship with returns, as shares with negative co-skewness will add to the downside exposure of a portfolio. Markets should therefore offer greater compensation as an incentive for holding these investments. As defined in equation (1), co-skewness is determined by the covariance of share returns with squared market returns, which is an indicator of market volatility. An investment with negative co-skewness should deliver relatively poorer returns when there is excess market volatility. Volatility is not particularly associated with either upturns or downturns, so no specific relationship can be identified with these separate periods. Any lack of symmetry in the distribution of co-skewness across upturn and downturn periods could however result in different relationships with returns. We expect high volatility during downturns. If this is a consistent outcome, negative co-skewness will be associated with relatively poorer returns. If excess volatility also occurs during upturns, investors holding these shares may also then experience poor returns. However, an overall positive reward for exposure to negative co-skewenss is likely, so we expect that investors will receive relatively higher returns during upturns. If volatility is more commonly associated with 
downturns, opposing relationships between co-skewness and returns may be identified in upturn and in downturn markets.

\section{Results}

\subsection{Ranked portfolios}

In this Section, we evaluate the importance of downside risk measures as indicators of realized returns. Related measures are included. If there is a cross-sectional relationship between returns and these measures, we expect to observe patterns between them.

- Table 3 approximately here-

Tests based on ranked equally weighted portfolios are presented in Table 3. In Panel A, we consider skewness of returns, as it is a widely reported feature of developing markets. Estimates for all companies in all years are ranked, and companies are then allocated to five equally weighted portfolios. Average skewness of firms allocated to each portfolio is recorded in the column headed 'Skew', and average daily returns is reported in the column headed 'Return'. Average portfolio values of variance (Var) and co-skewness (Cskw) are also recorded. We also show differences between highest and lowest ranked portfolios, and t-test statistics confirm the presence of a significant difference in returns. A first ranking presents results for the full study population. A second ranking only considers upturn years (designated Upturn Periods), whereas a final ranking (designated Downturn Periods) assesses returns in downturn years. We also test for significant differences between skewness of returns in upturns, and in downturns. A monotonic positive relationship between skewness and returns can be 
observed in the first set of rankings. We also find significant differences between returns in the highest and lowest ranked portfolios. Firms offering strong positive performance have positively skewed returns, whereas poorly performing firms exhibit negative skewness ${ }^{7}$. We assume investors accept lower returns on positively skewed investments, so our findings are contrary to expectations. Variance does not appear to be related to skewness, except that greater levels of positive and negative skewness are associated with higher variance. All portfolios exhibit relatively similar levels of co-skewness, suggesting little evidence of a relationship between volatility and coskewness. In subsequent testing, we examine this issue further. We note that a positive relationship between skewness and returns is retained in both upturn and downturn periods. Test statistics indicate that skewness is not particularly associated with either downturns or upturns. It is unsurprising therefore that this pattern is replicated in both sub-periods. In Panel B, we assess the explanatory power of variance. All portfolios are now based on ranked values of this measure. We concentrate on separate downturn and upturn periods, and we note that low variance portfolios tend to offer superior performance in both periods, although neither relationship is monotonic. Significant differences between highest and lowest ranked portfolios are only confirmed in downturn periods, when high variance is associated with negative returns. This is an anomalous relationship, but Ang, Hodrick, Xing, and Zhang (2006) also find that U.S. equities with high volatilities offer relatively lower returns. Test statistics indicate no difference in volatility between upturn and downturn periods. We also note that shares in the high variance portfolios exhibit excess negative co-skewness. An inverse relationship is indicated. Control tests are

\footnotetext{
${ }^{7}$ Arguably, these results follow by construction, as high skewness portfolios will have the greatest positive returns for a given in sample variance, and vice versa. We do not however control for variance in these portfolios.
} 
therefore required, as any relationship identified between co-skewness and returns may be partly explained by variance.

Panel C examines relationships between realized returns and co-skewness. Portfolios are formed by ranked estimates of co-skewness, so lower ranked portfolios exhibit more negative average values. We again concentrate on rankings for upturn and for downturn years. During downturns, investors holding shares with excess negative coskewness experience greater losses. This is a positive monotonic relationship. Excess negative co-skewness also implies greater losses during periods of volatility, which are typically associated with downturns. In contrast, during upturns, ranked portfolios indicate a reversed relationship between returns and co-skewness, as excess negative co-skewness offers the greatest rewards. This relationship also is monotonic.

Significant differences in returns between highest and lowest ranked portfolios confirm a benefit from negative co-skewness during upturns, and a loss during downturns. Test results also indicate significant differences between values in upturn and downturn periods. Lower (more negative) values suggest greater volatility during downturns. In Panel D, portfolios are formed using ranked estimates of downside beta. In this case we report average portfolio values for downside beta, and we exclude average skewness values. We again concentrate on upturn and downturn periods. Exposure to downside beta is rewarded with excess returns during upturns, and is penalized with losses during downturns. Upturn market findings conform with Ang, Chen, and Xing (2006), who report greater returns to high downside beta portfolios. We find an opposite relationship in downturn periods. We also note that portfolios with high downside beta shares have excess negative co-skewness, and vice 
versa. Any reward for exposure to negative co-skewness could be related to a reward for downside beta. We further examine this issue in subsequent sections.

\subsection{Control tests}

Negative co-skewness and downside beta both are indicators of downside risk. We therefore investigate the extent to which a premium for negative co-skewness is explained by, or is separate from a premium for downside beta. We investigate the reward for negative co-skewness, after controlling for downside beta, and vice versa. To control for downside beta, all shares are sorted into five quintiles, ranked on downside beta. Within each quintile, shares are then sorted into five equally weighted portfolios, using ranked values of co-skewness. This facilitates an investigation of the impact of negative co-skewness, as levels of downside beta should be close to identical in each quintile. An equivalent procedure facilitates the examination of returns for exposure to downside beta, after controlling for co-skewness. We report average realized returns for each portfolio. We also report differences in returns between highest and lowest ranked portfolios in each quintile, and average quintile returns. A t-test identifies significant differences in returns between highest and lowest ranked portfolios. In Table 4 Panel A, we investigate returns to investors accepting exposure to negative co-skewness, after controlling for downside beta. Panel B assesses rewards downside beta, after controlling for co-skewness. We report results for upturn and for downturn periods ${ }^{8}$.

- Table 4 approximately here-

\footnotetext{
${ }^{8}$ Control test results for combined upturn and downturn periods are available from the authors.
} 
In Panel A, across all quintiles, exposure to negative co-skewness generates rewards during upturns and poorer performance during downturns. These relationships are largely though not exclusively monotonic, and are confirmed by significant differences in returns between highest and lowest ranked portfolios. We therefore find that negative co-skewness has an independent contribution, separate from downside beta $^{9}$. We note that during downturns, in the lower downside beta quintiles, portfolios with greatest exposure to negative co-skewness offer noticeably better returns than the next ranked portfolios. As downside beta concentrates explicitly on downside market co-movements, very low downside beta shares should not experience major comovements during downturns. Excess negative co-skewness tends to be associated with poor performance when there is high market volatility, so a relatively better performance may indicate that very low downside beta values are recorded in low volatility markets. In Panel B, we note that, after controlling for the impact of coskewness, high downside beta portfolios offer poorer performance during downturns, but they compensate by offering relatively greater returns during upturns. This relationship is close to monotonic, and it is confirmed by significant differences in returns between highest and lowest ranked portfolios. This excess reward or excess punishment is most evident in quintiles with greatest exposure to negative coskewness. High downside beta investments which also exhibit negative co-skewness offer very poor performance during downturns, investors should however be

\footnotetext{
${ }^{9}$ An examination of test results on combined upturn and downturn periods suggests that an overall reward for exposure to negative co-skewness is limited to low downside beta quintiles. In higher downside beta quintiles, positive returns during upturns are cancelled out by negative returns during downturns.
} 
compensated by a very good performance in upturn markets ${ }^{10}$. In contrast, low downside beta shares should have less exposure to downside movements, even if they have excess negative coskewness. They therefore offer relatively good performance during downturns while also offering positive returns during upturns.

We use similar control tests to examine rewards for exposure to other combinations of risk factors ${ }^{11}$. Interrelationships between downside beta and variance are of interest, as variance is composed of systematic and unsystematic elements, and downside beta is closely related to beta, a measure of systematic risk. We previously identified anomalous relationships between variance and returns, as high variance portfolios offer inferior performance during upturns and superior returns during downturns. We find that these relationships are restricted to shares with low downside beta. In contrast, if there is a sizable exposure to downside beta, systematic risk dominates, resulting in a positive relationship between variance and returns during upturns and a negative relationship during downturns. We also find that the premium for downside beta is unexplained by variance, but levels of differentiation between high and low downside beta portfolios become progressively weaker with reduced variance. Variance is partly composed of systematic risk, so low variance will be associated with a greatly reduced spread in exposures to downside beta. When a control for coskewness is applied, the inverse relationship between variance and returns is limited to positive co-skewness quintiles. This relationship also is influenced by exposure to co-skewness. When there are high levels of negative co-skewness, we find a reward

\footnotetext{
${ }^{10}$ Test results on combined upturn and downturn data indicates that good performance during upturns is cancelled out by poor performance during downturns. A return for exposure to high downside beta over the entire study period therefore only is evident in positive co-skewness quintiles.

${ }^{11}$ For reasons of space, we present a summary outline of our results. Full details of these tests are available from the authors.
} 
for investment in high variance shares during upturns, and losses during downturns. We also confirm that a premium for negative co-skewness is not explained by variance, but in low variance quintiles we find a reduction in the degree of separation of returns. Both control tests therefore indicate that the inverse relationship between volatility and returns is limited to investments with low exposures to downside risk.

In summary, control tests confirm that exposure to negative co-skewness does differ from exposure to downside beta. Each is rewarded by excess returns during upturns, and is penalized by lower returns during downturns. These returns are not explained by variance. Anomalous relationships between variance and returns are restricted to shares with a low exposure to downside risk. A sizable exposure to either downside risk measure is associated with positive relationships between variance and returns during upturns, and negative relationships during downturns. We cannot offer an explanation for the variance-return puzzle noted by Ang, Hodrick, Xing and Zhang (2006), but our findings reveal the complexity of this relationship, and they suggest a partial explanation.

\subsection{Fama-MacBeth regressions}

In this Section, we use cross-sectional Fama and MacBeth (1973) regressions of excess returns on various risk estimates, as a further examination of the explanatory power of downside risk measures. As in all previous tests, twelve month horizons are employed, corresponding with the period over which risk measures are estimated. Equally weighted portfolios are employed, and excess returns are regressed on realized risk measures with respect to various sources of risk. Data from all markets and all years is considered. In order to assess the importance of these measures, both 
individually and in combination, we again split our data for upturn and for downturn periods. As a control test, we also include Fama and French (1993) factors, to determine if they capture downside risk concerns ${ }^{12}$.

- Table 5 approximately here-

Results of Fama-MacBeth regression tests are reported in Table $5^{13}$. Panel A offers regression results for the full sample, Panel B presents results from the same set of models on upturn period data, and Panel $\mathrm{C}$ offers results from the downturn periods. We note the rise in $\mathrm{R}^{2}$ due to a sample split, as in Pettengill et al (1995). Succeeding regression models assess the incremental contribution of individual of risk measures. As we concentrate on downside risk, our discussion focuses on Regression Model 8, which tests if a reward for both downside measures remains robust in the presence of variance and skewness of returns. In upturn periods, as expected, we find a negative coefficient on co-skewness (-2.029), and a positive coefficient on downside beta (0.512). The former is highly significant. The latter falls in value, if compared to results when idiosyncratic risk measures are excluded. It only retains significance at a 5\% level. This confirms findings from previous control tests (note Table 4 Panel A and B), except it suggests that downside beta is a more fragile explanatory measure. Compared to when idiosyncratic risk measures are not included, the coefficient on upside beta also falls in value, but it remains marginally significant $(-0.150)$. We find

\footnotetext{
${ }^{12}$ We prepare daily SMB and HML factors for each market, in the conventional way. We then estimate annual betas in relation to these factors. These betas $(\beta(S M B)$ and $\beta(H M L))$ are included as explanatory factors in a final series of regression tests.

${ }^{13}$ We do not apply Shanken (1992) correction factors. Jagannathan and Wang (1996) report that “generalizing Shanken's work, the Fama Macbeth procedure does not in fact overestimate the precision of coefficient estimates"
} 
similar results in downturn periods. As expected, the coefficient on co-skewness is positive and highly significant $(0.516)$. The coefficient on downside beta is negative, but only significant at a $5 \%$ level (-0.572). Upside beta carries a marginally significant positive coefficient (0.306). Coefficients for skewness are positive and highly significant, when tested on both upturn and downturn data (0.381 and 0.394 respectively). This outcome is unaffected by the inclusion of all other risk measures. Variance is significant, is inversely related to returns during upturn periods (-0.027) and is directly related during downturns (0.008). The negative relationship is anomalous, but it confirms our portfolio based findings (Section 4.1). A positive relationship during downturns could also be considered anomalous. It implies that exposure to excess volatility is associated with relatively better performance. If we consider results for combined upturn and downturn data, we find a marginally positive coefficient on co-skewness (0.209). An examination of ranked portfolios formed from the full dataset (Section 4.1) suggests an unclear relationship, as shares with average exposures offer highest returns. This result is therefore unsurprising.

In Model 9, downside beta is replaced by relative downside beta and upside beta is replaced by relative upside beta. Results are largely unchanged. Co-skewess coefficients again carry the correct signs and remain highly significant in both upturn and downturn periods (-2.147 and 0.553). Coefficients on variance and skewness are unaffected. Upturn market coefficients on relative downside beta and relative upside beta are 0.204 and -0.172 respectively, downturn market coefficients are -0.264 and 0.725. All carry correct signs. We also confirm that, after allowing for regular beta, downside and upside beta retain incremental explanatory power, as we note significant coefficients for beta, relative downside beta, and relative upside beta in 
Regression Model 4 (upturn and downturn periods). The inclusion of exposures SMB and HML factors has little impact on the explanatory power of downside risk measures in developing markets. Model 8 offers a robustness test on Model 6, and a comparison between estimates indicates no impact on co-skewness. Downside and upside beta also are unaffected, but when compared to co-skewness, they have more fragile explanatory power. Idiosyncratic risk factors are unaffected by the inclusion of exposures to SMB and HML.

Using cross-sectional means and standard deviations of risk factor loadings, we assess the economic significance of our results. We use estimated coefficients from Model 8 when determining risk premiums. In upturn periods, the risk premium for downside beta is 0.133 , or $13.3 \%(0.000512 \times 260)^{14}$. Average downside beta is 0.934 with a standard deviation of 0.671 , so the reward for this exposure is $12.4 \%(0.934 \times 13.3)$, with a standard deviation of $8.9 \%(0.671 \times 13.3)$. Negative co-skewness risk premium is -0.0053 or- $0.53 \%(-0.00002029 \times 260)^{15}$. As average co-skewness is -13.707 , with a standard deviation of 61.47 , the average reward for negative co-skewness is $7.23 \%$ ($13.707 \mathrm{x}-0.53)$, with a standard deviation of $32.4 \%(61.47 \mathrm{x} 0.53)$. The rewards for downside beta and negative co-skewness reinforce each other, but negative coskewness offers a lower reward than downside beta, and greater return variability. In downturn periods, an annual exposure of -0.149 or $-14.9 \%(-0.000572 \times 260)$ for downside beta implies that losses for average exposure will be $-12.9 \%(0.865 x-14.9)$, with a standard deviation of $13.1 \%(0.874 \times 0.149)$. Average downside beta is 0.865 ,

\footnotetext{
${ }^{14}$ Coefficients have been estimated using daily returns. As annual risk premiums are more meaningful, we multiply all coefficients by 260 , the number of trading days assumed in a calendar year.

${ }^{15}$ As previously discussed in section 4.1, exposure to negative co-skewness implies increasing risk. Negative coefficients during upturn periods therefore indicate rewards, whereas positive coefficients during downturns demonstrate losses.
} 
with a standard deviation of 0.874 . We estimate that annual exposure for negative coskewness is 0.001342 , or $0.13 \%(0.00000516 \times 260)$. Average co-skewness is -38.14 with a standard deviation of 125.51 , so the losses for an average co-skewness exposure are $-5.2 \%(-38.14 \times 0.13)$, with a standard deviation of $16.8 \%(125.51 \times 0.13)$. The losses for downside beta and for negative co-skewness again reinforce each other, Premium paid for exposure to negative co-skewness again is lower than that for downside beta and it varies to a greater extent. For both downside exposures, any benefits received during upturn periods are of a similar scale to any losses experienced during downturns.

Table 5 offers a consistent message. Investors accepting exposure to negative coskewness are rewarded during market upturns, but they experience losses during downturns. This finding is robust to the inclusion of other risk measures. Downside beta shares offer higher returns in upturn periods, accompanied by greater losses during downturns. This result also is robust to the inclusion of other risk factors. Coefficients on downside beta retain only five percent significance in some tests. Negative co-skewness and downside beta remain priced when assessed together, indicating that investors consider them to be separate risk exposures. Results for upside beta are similar to those for downside beta, suggesting that it continues to be priced, even in the presence of idiosyncratic risk measures. We find no evidence that the extended Fama-French factors fully capture downside risk concerns.

\section{Conclusions}

We find evidence of relationships between downside risk measures and returns on individual shares in emerging Asian markets. Our measures are negative co-skewness 
and downside beta. In a separate investigation of upturn and downturn markets, we find that both are priced. In upturn markets, exposure to negative co-skewness and to downside beta is rewarded with larger returns. These exposures are penalized with greater losses during downturns. If upturn and downturn data is combined, average returns obscure the pricing relationship. We do not however believe that this implies major differences between emerging and developed markets, as previous research did not include a separate analysis of upturns and downturns. Our findings are not directly comparable. Control tests confirm that each downside risk is separately priced. They do not capture similar effects in company returns. When combined with other risk measures, we find that downside beta has reduced significance. There is no evidence of a reduced significance for co-skewness. During upturn years, we estimate an average premium of $7 \%$ for negative co-skewness risk, and an average premium of $12 \%$ for downside beta risk. We estimate losses of a similar scale during downturns.

\section{Acknowledgements}

We wish to acknowledge valuable comments on earlier drafts that were provided by participants at the 2011 Multinational Finance Society Meeting, and by anonymous referees. Any remaining errors are ours.

\section{References}

Ang, A., Chen, J., Xing, Y., 2006. Downside risk. The Review of Financial Studies 19, 1191-1239.

Ang, A., Hodrick, R.J., Xing, Y., Zhang X., 2006. The cross-section of volatility and expected stock returns. Journal of Finance 51, 259-299. 
Bawa, V., Lindenberg, E., 1977. Capital market equilibrium in a mean-lower partial moment framework. Journal of Financial Economics 5, 189-200.

Bekaert, G., Harvey C., 1997. Emerging equity market volatility. Journal of Financial Economics, 43, 29-77.

Bekaert, G., Erb, C., Harvey, C., Viskanta, T., 1998. Distributional characteristics of emerging market returns, and asset allocation. The Journal of Portfolio Management 24, 102-116.

Estrada, J., 2002. Systematic risk in emerging markets: The D-CAPM. Emerging Markets Review 3, 365-379.

Fama,E.F., French, K., 1993.Common risk factors in the returns on stocks and bonds. Journal of Financial Economics 33, 3-56.

Fama, E.F., MacBeth, J.D., 1973. Risk, return, and equilibrium: Empirical tests. Journal of Political Economy 71, 607-636.

Feldman, R., Kumar, M., 1995. Emerging equity markets: Growth, benefits, and policy concerns. The World Bank Research Observer 10, 181-200. 
Galagedera, D., and Brooks, R.D., 2007. Is co-skewness a better measure of risk in the downside than downside beta? Evidence in emerging market data. Journal of Multinational Financial Management 17, 214-230.

Galagedera, D., 2009. Economic significance of downside risk in developed and emerging markets. Applied Economics Letters 16, 1627-1632.

Gul, F., 1991. A theory of disappointment aversion. Econometrica 59, 667-686.

Harvey, C.R., Siddique, A., 2000. Conditional skewness in asset pricing tests. Journal of Finance 60, 1263-1295.

Huang, C-F., Litzenberger, R., 1988. Foundations for Financial Economics. NorthHolland, New York.

Ince, O.S., Porter, R., 2006. Individual equity return data from Thomson Data-stream: Handle with care! Journal of Financial Research 29, 463-473.

Jagannathan, R., Wang, Z., 1996. The conditional CAPM and the cross-section of expected returns. Journal of Finance 51, 3-53.

Kothari, S., Shanken, J., Sloan, R., 1995. Another look at the cross-section of expected stock returns. Journal of Finance 50, 185-224. 
Kraus, A., Litzenberger, R., 1976. Skewness preference and the valuation of risk assets. Journal of Finance 31, 1085-1100.

Lesmond, D., Ogden, J., Trzcinka, C., 1999. A new estimate of transaction costs. The Review of Financial Studies 12, 1113-1141.

Lewellen, J., Nagel, S., 2006. The conditional CAPM does not explain asset-pricing anomalies. Journal of Financial Economics 82, 289-314.

Pedersen, C., Hwang, S., 2007. Does downside beta matter in asset pricing? Applied Financial Economics 17, 961-978.

Pettengill, G.N., Sundaram, S., Mathur, I, 1995. The conditional relation between beta and returns. Journal of Financial and Quantitative Analysis, 30, 101-116.

Shanken, J., 1992. On the estimation of beta pricing models. Review of Financial Studies 5, 1-34.

Wang, J., 2007. Foreign equity trading and emerging market volatility: Evidence from Indonesia and Thailand. Journal of Development Economics, 84, 798-811. 
Table 1

Outline details, emerging Asian stock markets.

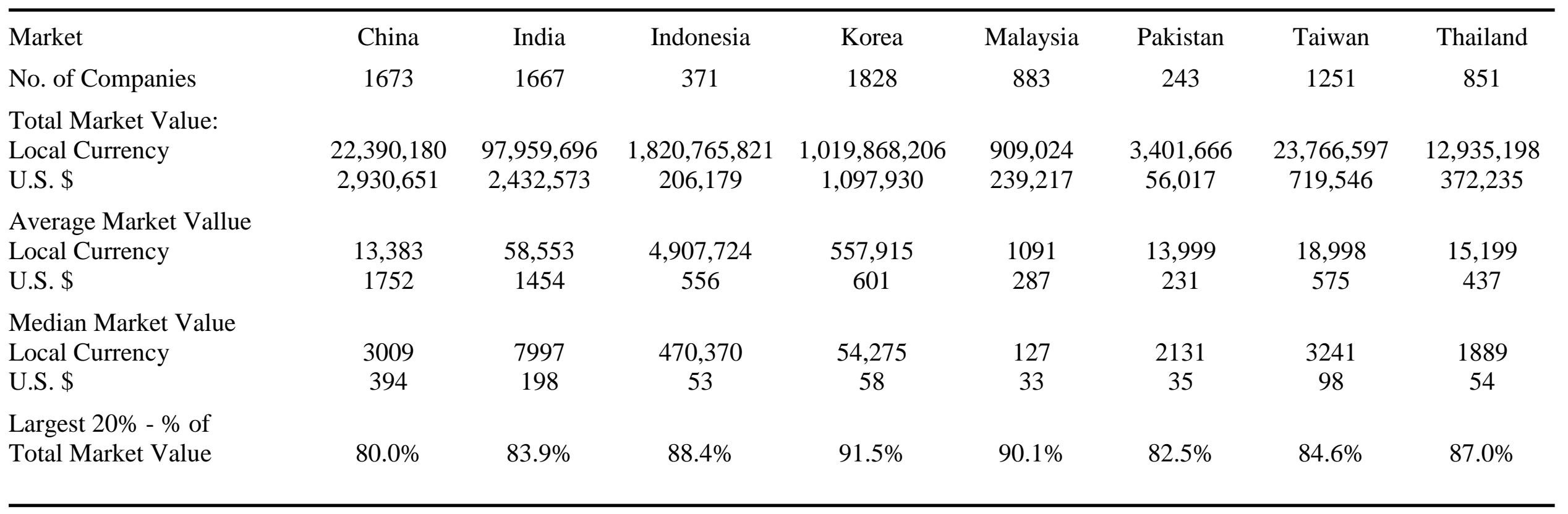

Note: All amounts and values are as on June $1^{\text {st }} .2008$. All values are multiples of one million. Chinese values are expressed in Renminbi, Indian values are expressed in Indian Rupees, Indonesian values are expressed in Indonesian Rupiah, Korean values are expressed in South Korean Won, Malaysian values are expressed in Malaysian Ringgit, Pakistani values are expressed in Pakistani Rupees, Taiwanese values are expressed in Taiwanese Dollars, and Thailand Values are expressed in Thai Baht. US \$ values are estimated using the appropriate exchange rate on June $1^{\text {st }}$ 2008. 
Table 2

Relationship between investor exposure to individual risk measures, and investor returns.

\begin{tabular}{cccc}
\hline & & & \\
Risk Measure & All Periods & Upturn Periods & Downturn Periods \\
Variance & Positive & Not Specified & Not Specified \\
Skewness & Negative & Not Specified & Not Specified \\
Market Beta & Positive & Positive & Negative \\
Downside Beta & Positive & Not Specified & Negative \\
Upside Beta & Negative & Positive & Not Specified \\
Co-skewness & Negative & Not Specified & Not Specified \\
\hline
\end{tabular}


Table 3

Share portfolios ranked by risk factor loadings

Panel A: Skewness of Returns (Skew)

\begin{tabular}{|c|c|c|c|c|}
\hline \multicolumn{4}{|c|}{ All Periods } & \multirow[b]{2}{*}{ Cskw } \\
\hline Portfolio & Return & Skew & Var & \\
\hline 1 & 4.567 & 8.89 & 12.02 & -3.87 \\
\hline 2 & 0.382 & 0.58 & 0.92 & -0.63 \\
\hline 3 & 0.033 & 0.14 & 1.17 & -1.19 \\
\hline 4 & -0.024 & -0.19 & 1.15 & -1.96 \\
\hline 5 & -4.286 & -8.39 & 11.67 & -5.07 \\
\hline $1-5$ & $8.853^{* *}$ & 17.28 & 0.03 & 1.21 \\
\hline
\end{tabular}

Panel B: Variance of Returns (Var)

\begin{tabular}{ccccc}
\multicolumn{5}{c}{ All Periods } \\
\cline { 1 - 4 } Portfolio & Return & Skew & Var & Cskw \\
1 & 0.094 & 0.56 & 22.66 & -7.65 \\
2 & -0.609 & 0.04 & 2.26 & -3.18 \\
3 & 0.283 & 0.07 & 1.09 & -1.19 \\
4 & 0.493 & 0.12 & 0.63 & -0.50 \\
5 & 0.412 & 0.25 & 0.30 & -0.19 \\
$1-5$ & $-0.318^{*}$ & 0.30 & 22.36 & -7.46
\end{tabular}

Upturn Periods

\begin{tabular}{ccccc}
\hline Portfolio & Return & Skew & Var & Cskw \\
1 & 4.980 & 9.98 & 12.78 & -5.26 \\
2 & 0.745 & 0.72 & 0.81 & -0.49 \\
3 & 0.501 & 0.17 & 0.86 & -0.72 \\
4 & 0.547 & -0.17 & 0.98 & -1.07 \\
5 & -4.503 & -9.03 & 11.69 & 0.69 \\
$1-5$ & $9.483^{* *}$ & 19.01 & 1.08 & -5.95
\end{tabular}

Upturn Periods

\begin{tabular}{ccccc}
\hline Portfolio & Return & Skew & Var & Cskw \\
1 & 0.337 & 0.84 & 23.09 & -3.69 \\
2 & -0.054 & 0.10 & 2.12 & -1.32 \\
3 & 0.618 & 0.19 & 1.03 & -1.13 \\
4 & 0.817 & 0.27 & 0.58 & -0.53 \\
5 & 0.555 & 0.29 & 0.28 & -0.18 \\
$1-5$ & -0.218 & 0.55 & 22.81 & -3.51
\end{tabular}

Downturn Periods

\begin{tabular}{ccccc}
\multicolumn{7}{c}{ Downturn Periods } & \multicolumn{1}{c}{ Cskw } \\
\cline { 1 - 4 } Portfolio & Return & Skew & Var & Cskw \\
1 & 3.992 & 7.64 & 11.25 & -2.40 \\
2 & -0.002 & 0.47 & 1.17 & -0.74 \\
3 & -0.404 & 0.12 & 1.34 & -1.77 \\
4 & -0.619 & -0.21 & 1.31 & -2.87 \\
5 & -4.035 & -7.70 & 11.65 & -11.29 \\
$1-5$ & $8.027^{* *}$ & 15.34 & -0.40 & 8.89
\end{tabular}

Downturn Periods

\begin{tabular}{ccccc}
\hline Portfolio & Return & Skew & Var & Cskw \\
1 & -0.215 & 0.23 & 22.16 & -12.06 \\
2 & -1.111 & -0.01 & 2.41 & -4.84 \\
3 & -0.064 & -0.05 & 1.15 & -1.55 \\
4 & 0.137 & -0.03 & 0.66 & -0.43 \\
5 & 0.189 & 0.18 & 0.33 & -0.19 \\
$1-5$ & $-0.405^{*}$ & 0.05 & 21.83 & -11.87
\end{tabular}


Panel C: Co-skewness of Returns (Cskw)

\begin{tabular}{|c|c|c|c|c|}
\hline \multicolumn{4}{|c|}{ All Periods } & \multirow[b]{2}{*}{ Cskw } \\
\hline Portfolio & Return & Skew & Var & \\
\hline 1 & -0.710 & -0.46 & 8.26 & 3.38 \\
\hline 2 & 0.460 & 0.12 & 0.90 & 0.05 \\
\hline 3 & 0.434 & 0.38 & 1.31 & -0.39 \\
\hline 4 & 0.192 & 0.13 & 3.07 & -2.09 \\
\hline 5 & 0.295 & 0.86 & 13.38 & -13.66 \\
\hline $1-5$ & $-1.005^{* *}$ & -1.32 & -5.12 & 17.02 \\
\hline
\end{tabular}

\begin{tabular}{|c|c|c|c|c|}
\hline \multicolumn{4}{|c|}{ Upturn Periods } & \multirow[b]{2}{*}{ Cskw } \\
\hline ortfolio & Return & Skew & Var & \\
\hline 1 & -3.0 & -3.72 & 9.70 & 2.96 \\
\hline 2 & 0.4 & 0.06 & 1.06 & 0.04 \\
\hline 3 & 0.6 & 0.57 & 1.16 & -0.29 \\
\hline 4 & 0.6 & 0.87 & 2.88 & -1.23 \\
\hline 5 & 3.560 & 3.92 & 12.32 & -8.3 \\
\hline $1-5$ & $-6.564^{* * *}$ & -7.64 & -2.62 & 11.2 \\
\hline
\end{tabular}

\begin{tabular}{ccccc}
\multicolumn{4}{c}{ Downturn Periods } & \\
\cline { 1 - 4 } Portfolio & Return & Skew & Var & Cskw \\
1 & 1.779 & 3.06 & 6.69 & 3.82 \\
2 & 0.476 & 0.23 & 0.74 & 0.06 \\
3 & -0.061 & -0.24 & 1.49 & -0.67 \\
4 & -1.086 & -0.82 & 2.72 & -3.68 \\
5 & -2.174 & -1.89 & 15.08 & -18.61 \\
$1-5$ & $3.953^{* *}$ & 4.95 & -8.38 & 22.43
\end{tabular}

Panel D: Downside Beta $\left(\beta^{-}\right)$

\begin{tabular}{ccccc}
\multicolumn{5}{c}{ All Periods } \\
\cline { 1 - 4 } Portfolio & Return & $\beta$ & Var & Cskw \\
1 & 0.281 & 1.83 & 9.62 & -7.52 \\
2 & 0.177 & 1.19 & 3.31 & -2.53 \\
3 & 0.116 & 0.91 & 2.99 & -1.71 \\
4 & -0.044 & 0.60 & 3.32 & -1.42 \\
5 & 0.141 & -0.03 & 7.69 & 0.46 \\
$1-5$ & 0.140 & 1.86 & 1.93 & -7.98
\end{tabular}

\begin{tabular}{|c|c|c|c|c|}
\hline \multicolumn{4}{|c|}{ Upturn Periods } & \multirow[b]{2}{*}{ Cskw } \\
\hline Portfolio & Return & $\beta^{-}$ & Var & \\
\hline 1 & 2.676 & 1.82 & 9.72 & -4.48 \\
\hline 2 & 0.967 & 1.23 & 3.43 & -1.86 \\
\hline 3 & 0.567 & 0.94 & 2.82 & -1.17 \\
\hline 4 & -0.136 & 0.62 & 3.25 & -0.42 \\
\hline 5 & -1.803 & 0.05 & 7.91 & 1.08 \\
\hline $1-5$ & $4.479^{* * *}$ & 1.77 & 1.81 & -5.56 \\
\hline
\end{tabular}

\begin{tabular}{ccccc}
\multicolumn{5}{c}{ Downturn Periods } \\
\cline { 2 - 4 } Portfolio & Return & $\beta$ & Var & Cskw \\
1 & -2.549 & 1.85 & 9.53 & -11.15 \\
2 & -0.659 & 1.15 & 3.25 & -3.08 \\
3 & -0.237 & 0.88 & 3.21 & -2.45 \\
4 & 0.170 & 0.58 & 3.26 & -2.29 \\
5 & 2.213 & -0.13 & 7.48 & -0.09 \\
$1-5$ & $-4.762^{* *}$ & 1.98 & 2.05 & -11.06
\end{tabular}

Note: This table lists equally weighted average excess returns and risk characteristics of quintile portfolios formed from shares ranked by skewness of share returns (Panel A), variance of share returns (Panel B), co-skewness of share returns (Panel C), and downside beta (Panel D). All risk measures are estimated over the same one-year time period as average realized returns. In the case of each risk measure, ranked portfolios are formed using all recorded realized returns (All Periods), all recorded realized returns during upturn years (Upturn Periods), and all 
recorded realized returns during downturn years (Downturn Periods). Average portfolio returns and average values of risk measures are shown for all ranked portfolios. We also show, in row 1-5, differences in values between highest and lowest ranked portfolios. We use t-statistics to test for significant differences between highest and lowest ranked portfolio average returns. $*$ and $* *$ indicate statistically significant differences, at the 5\% and $1 \%$ levels. We also test for evidence of differences between levels of individual firm risk characteristics in upturn and in downturn periods. We again use 't-test' statistics to identify significant differences in levels of Skewness, of Variance, and of Co-skewness. Results are reported and discussed in the text. In Panel D, we report downside beta values rather than skewness values. Returns are average daily returns $\left(\mathrm{x} 10^{3}\right)$. Variance is $\left(\mathrm{x} 10^{3}\right)$, and co-skewness is $\left(\times 10^{-1}\right)$. 
Table 4

Co-skewness and Downside Beta Control Tests

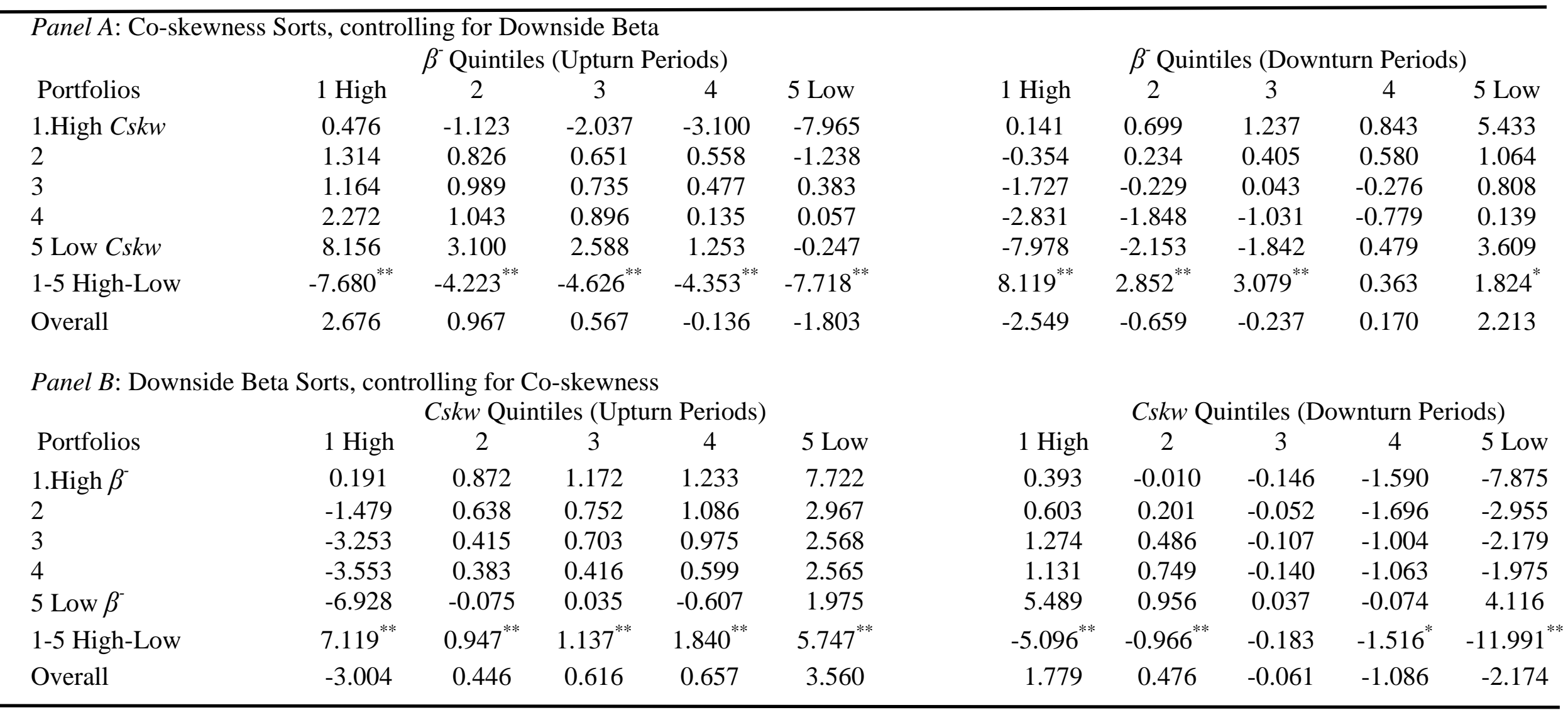

Note: This table offers an examination of the relationship between co-skewness and downside beta. Using the full dataset, annual values of each measure are estimated. In Panel A, shares are firstly ranked into quintiles, based on downside beta. Within each quintile, shares are then ranked by co-skewness for the same period. Shares are allocated to five further portfolios. In Panel B, shares are firstly ranked into quintiles, based on 
co-skewness. Within each quintile, shares are then ranked by downside beta for the same period, and are allocated to five further portfolios. We report equally weighted average daily realized returns $\left(\times 10^{3}\right)$ generated by each portfolio. We also show, in row 1-5, differences in returns between highest and lowest ranked portfolios. We use t-statistics to test for significant differences between highest and lowest ranked portfolios. $*$ and ** indicate statistically significant differences at the 5\% and $1 \%$ levels. For purposes of comparison, we include overall results for each quintile. We present separate results for individual years when returns above their risk-free rates (Upturn Periods), and when returns below their risk-free rates (Downturn Periods). 
Table 5

Fama-McBeth Regressions

\begin{tabular}{|c|c|c|c|c|c|c|c|c|c|}
\hline \multicolumn{10}{|c|}{ Panel A: All Periods } \\
\hline Model & 1 & 2 & 3 & 4 & 5 & 6 & 7 & 8 & 9 \\
\hline Intercept & $0.223^{*}$ & $0.102 *$ & $0.543^{*}$ & $0.351^{*}$ & $0.481^{*}$ & 0.011 & $0.092^{*}$ & 0.341 & 0.050 \\
\hline$C s k w$ & $0.347^{*}$ & $0.207 *$ & & & $0.391^{*}$ & $0.296^{*}$ & $0.299^{*}$ & $0.209^{*}$ & $0.199^{*}$ \\
\hline Var & & -0.005 & & & & -0.004 & -0.004 & -0.004 & -0.004 \\
\hline Skew & & $0.546^{* *}$ & & & & $0.545^{* *}$ & $0.545^{* *}$ & $0.449^{* *}$ & $0.448^{* *}$ \\
\hline$\beta^{-}$ & & & -0.257 & & 0.016 & 0.161 & & 0.092 & \\
\hline$\beta^{+}$ & & & $-0.237^{*}$ & & $-0.345^{*}$ & $-0.180^{*}$ & & -0.073 & \\
\hline$\beta$ & & & & -0.234 & & & & & \\
\hline $\operatorname{Rel}\left(\beta^{-}\right)$ & & & & $-0.704^{*}$ & & & 0.177 & & 0.061 \\
\hline $\operatorname{Rel}\left(\beta^{+}\right)$ & & & & $-0.477^{*}$ & & & $-0.165^{*}$ & & -0.082 \\
\hline$\beta(S M B)$ & & & & & & & & $-0.631^{* *}$ & $-0.631^{* *}$ \\
\hline$\beta(H M L)$ & & & & & & & & $-0.551^{* *}$ & $-0.551^{* *}$ \\
\hline $\operatorname{Adj} . R^{2}$ & 0.006 & 0.629 & 0.005 & 0.011 & 0.010 & 0.631 & 0.631 & 0.672 & 0.672 \\
\hline \multicolumn{10}{|c|}{ Panel B: Upturn Periods } \\
\hline Model & 1 & 2 & 3 & 4 & 5 & 6 & 7 & 8 & 9 \\
\hline Intercept & $-0.149^{*}$ & $0.129^{*}$ & $-1.743^{* *}$ & $-1.958^{* *}$ & $-1.193^{* *}$ & $-0.259^{*}$ & $0.096^{*}$ & $-0.228^{*}$ & $0.086^{*}$ \\
\hline$C s k w$ & $-4.405^{* *}$ & $-2.489^{* *}$ & & & $-3.124^{* *}$ & $-2.164^{* *}$ & $-2.308^{* *}$ & $-2.029^{* *}$ & $-2.147^{* *}$ \\
\hline Var & & $-0.030^{* * *}$ & & & & $-0.028^{* * *}$ & $-0.029^{* *}$ & $-0.027^{* *}$ & $-0.028^{* *}$ \\
\hline Skew & & $0.439^{* *}$ & & & & $0.415^{* *}$ & $0.422^{* *}$ & $0.381^{* *}$ & $0.385^{* *}$ \\
\hline
\end{tabular}




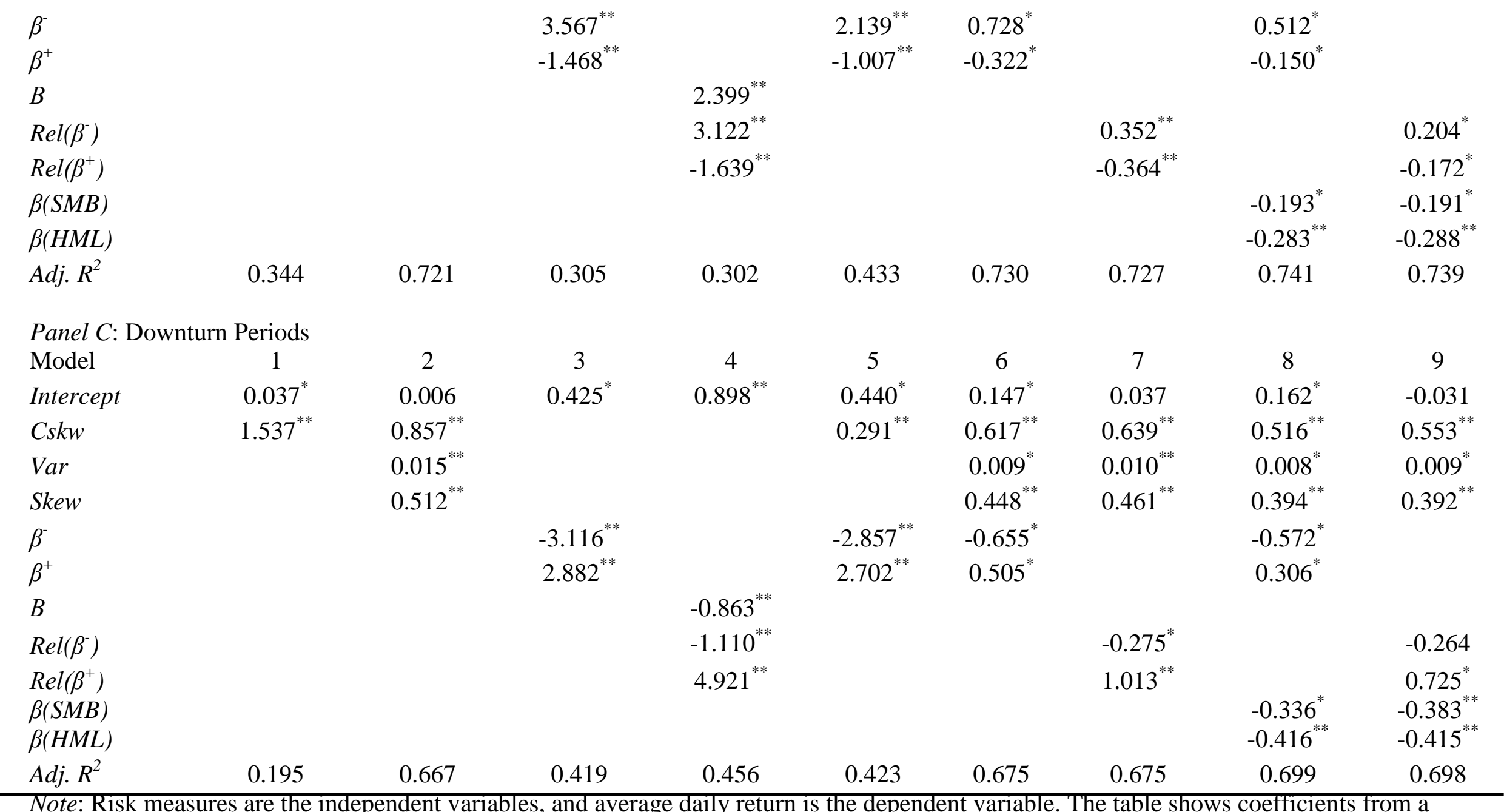

Fama-McBeth regression of twelve month average daily portfolio returns on portfolio risk characteristics. Coefficients from various models are 
presented. The following coefficients are multiplied by $10^{3}$ : Intercept, skewness, beta, downside beta, upside beta, relative downside beta, relative upside beta, beta $(S M B)$, and beta $(H M L)$. The coefficient for co-skewness is multiplied by $10^{5} . *$ and ** indicate statistically significant coefficients, at the $5 \%$ and $1 \%$ levels, respectively. Model goodness of fit is indicated by adjusted $\mathrm{R}^{2}$ s. 